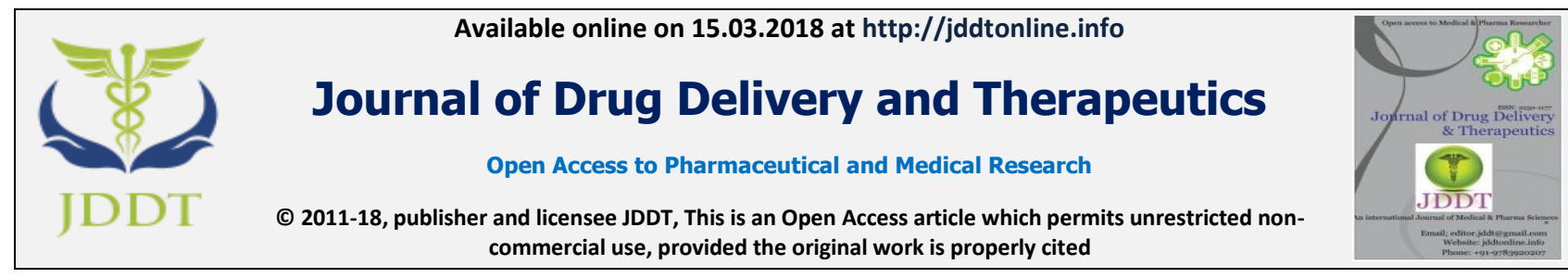

Open $\odot$ Access

Review Article

\title{
STABILITY TESTING GUIDELINEs OF PHARMACEUTICAL PRODUCTs
}

\author{
Megha Pokharana*, Rajat Vaishnav, Anju Goyal, Aseem Shrivastava \\ B.N. Institute of Pharmaceutical Sciences, Udaipur (Raj.) 313001, India
}

\begin{abstract}
Stability studies of pharmaceutical products ensuring the maintenance of product quality, safety and efficacy throughout the shelf life are considered as pre-requisite for the acceptance and approval of any pharmaceutical product. Stability of a pharmaceutical product may be defined as the capability of a particular formulation in a specific container/closure system to remain within its physical, chemical, microbiological, toxicological, protective and informational specifications. Stability studies are required to be conducted in a planned way following the guidelines issued by ICH, who and or other agencies. Importance of various methods followed for stability testing of pharmaceutical products, guidelines issued for stability testing and other aspects related to stability of pharmaceutical products have been included in the present review
\end{abstract}

Keywords: stability testing, stability studies, stability, pharmaceutical products, international council for harmonisation

Article Info: Received 02 Dec, 2017; Review Completed 22 Feb, 2018; Accepted 27 Feb, 2018; Available online 15 March, 2018

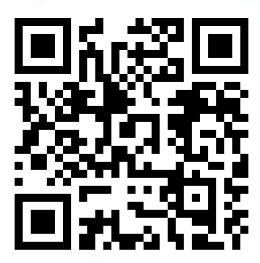

\section{Cite this article as:}

Pokharana M, Vaishnav R, Goyal A, Shrivastava A, Stability testing guidelines of pharmaceutical products, Journal of Drug Delivery and Therapeutics. 2018; 8(2):169-175

DOI: http://dx.doi.org/10.22270/jddt.v8i2.1564

*Address for Correspondence

Megha Pokharana, B.N. Institute of Pharmaceutical Sciences' Udaipur (Raj.) 313001, India.

\section{INTRODUCTION}

Stability testing of pharmaceutical products is a complex set of procedures involving considerable cost, time consumption and scientific expertise in order to build in quality, efficacy and safety in a drug formulation ${ }^{1}$. Scientific and commercial success of a pharmaceutical product can only be ensured with the understanding of the drug development process and the myriad tasks and milestones that are vital to a comprehensive development plan. The most important steps during the developmental stages include pharmaceutical analysis and stability studies that are required to determine and assure the identity, potency and purity of ingredients, as well as those of the formulated products ${ }^{2}$. Stability of a pharmaceutical product may be defined as the capability of a particular formulation in a specific container/closure system to remain within its physical, chemical, microbiological, toxicological, protective and informational specifications ${ }^{3,4}$. In other words, it is the extent to which a product retains, within the specified limits, throughout its period of storage and use, the same properties and characteristics possessed at the time of its packaging. Stability testing thus evaluates the effect of environmental factors on the quality of the a drug substance or a formulated product which is utilized for prediction of its shelf life, determine proper storage conditions and suggest labelling instructions. Moreover, the data generated during the stability testing is an important requirement for regulatory approval of any drug or formulation ${ }^{2}$.

\section{SIGNIFICANCE OF STABILITY TESTING}

The primary reason for stability testing is the concern for the well-being of the patient suffering from the disease for which the products is designed. Apart from degradation of the unstable product into toxic decomposition products, loss of activity up to a level of $85 \%$ of that claimed on the label may lead to failure of the therapy resulting in death e.g. nitroglycerine tablets for angina and cardiac arrest. Because of this concern, it has become a legal requirement to provide data for certain types of stability tests for the regulatory agencies before approval of a new product. Second important 
concern is to protect the reputation of the manufacturer by assuring that the product will retain fitness for use with respect to all functionally relevant attributes for as long as they are on the market. Other benefits of stability studies at the developmental stage or of the marketed products are to provide a database that may be of value in selection of adequate formulations, excipients and container closure systems for development of a new product, to determine shelf life and storage conditions for development of a new product, preparation of registration dossier, to substantiate the claimed shelf life for the registration dossier and to verify that no changes have been introduced in the formulation or manufacturing process that can adversely affect the stability of the product ${ }^{2,5}$.

\section{STABILITY TESTING METHOD}

Stability testing is a routine procedure performed on drug substances and products and is employed at various stages of the product development. In early stages, accelerated stability testing (at relatively high temperatures and/or humidity) is used in order to determine the type of degradation products which may be found after long-term storage. Testing under less rigorous conditions i.e. those recommended for longterm shelf storage, at slightly elevated temperatures is used to determine a product's shelf life and expiration dates. Depending upon the aim and steps followed, stability testing procedures have been categorized into the following four types:

1. Real Time stability testing

2. Accelerated stability testing

3. Retained sample stability testing

4. Cyclic temperature stress testing

\section{Real-time stability testing:}

Real-time stability testing is normally performed for longer duration of the test period in order to allow significant product degradation under recommended storage conditions. The period of the test depends upon the stability of the product which should be long enough to indicate clearly that no measurable degradation occurs and must permit one to distinguish degradation from inter-assay variation. During the testing, data is collected at an appropriate frequency such that a trend analysis is able to distinguish instability from day-to-day ambiguity.

Stability of the reference material also includes the stability of reagents as well as consistency of the performance of the instrument to be used throughout the period of stability testing. However, system performance and control for drift and discontinuity resulting from changes in both reagents and instrumentation must be monitored $^{6}$.

\section{DRUG PRODUCT STABILITY TESTING SYSTEM}

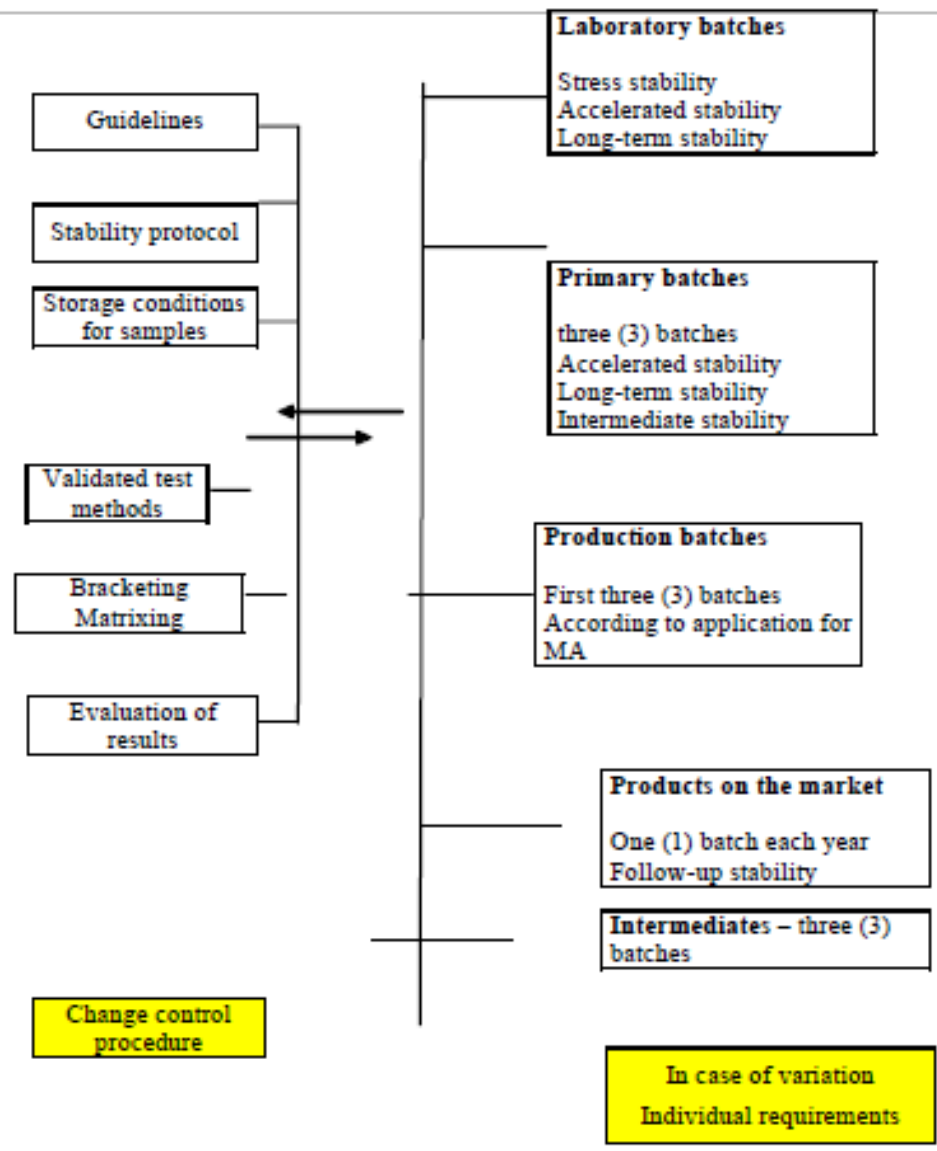

Figure 1: Drug product stability testing system. 


\section{Accelerated stability testing:}

In accelerated stability testing, a product is stressed at several high (warmer than ambient) temperatures and the amount of heat input required to cause product failure is determined. This is done to subject the product to a condition that accelerates degradation. This information is then projected to predict shelf life or used to compare the relative stability of alternative formulations. This usually provides an early indication of the product shelf life and thus shortening the development schedule. In addition to temperature, stress conditions applied during accelerated stability testing are moisture, light, agitation, gravity, $\mathrm{pH}$ and package ${ }^{3}$. In accelerated stability testing the samples are subjected to stress, refrigerated after stressing, and then assayed simultaneously. Because the duration of the analysis is short, the likelihood of instability in the measurement system is reduced in comparison to the real-time stability testing. Further, in accelerated stability testing, comparison of the unstressed product with stressed material is made within the same assay and the stressed sample recovery is expressed as percent of unstressed sample recovery. For statistical reasons, the treatment in accelerated stability projections is recommended to be conducted at four different stress temperatures. However, for thermolabile and proteinaceous components, relatively accurate stability projections are obtained when denaturing stress temperatures are avoided $^{6}$.

\section{Retained sample stability testing:}

This is a usual practice for every marketed product for which stability data are required. In this study, stability samples, for retained storage for at least one batch a year are selected. If the number of batches marketed exceeds 50, stability samples from two batches are recommended to be taken. At the time of first introduction of the product in the market, the stability samples of every batch may be taken, which may be decreased to only $2 \%$ to $5 \%$ of marketed batches at a later stage. In this study, the stability samples are tested at predetermined intervals i.e. if a product has shelf life of 5 years, it is conventional to test samples at 3, 6, 9, $12,18,24,36,48$, and 60 months. This conventional method of obtaining stability data on retained storage samples is known as constant interval method ${ }^{3,5}$.

\section{Cyclic temperature stress testing:}

This is not a routine testing method for marketed products. In this method, cyclic temperature stress tests are designed on knowledge of the product so as to mimic likely conditions in market place storage. The period of cycle mostly considered is 24 hours since the diurnal rhythm on earth is 24 hour, which the marketed pharmaceuticals are most likely to experience during storage. The minimum and maximum temperatures for the cyclic stress testing is recommended to be selected on a product by-product basis and considering factors like recommended storage temperatures for the product and specific chemical and physical degradation properties of the products. It is also recommended that the test should normally have 20 cycles $^{3,5}$.

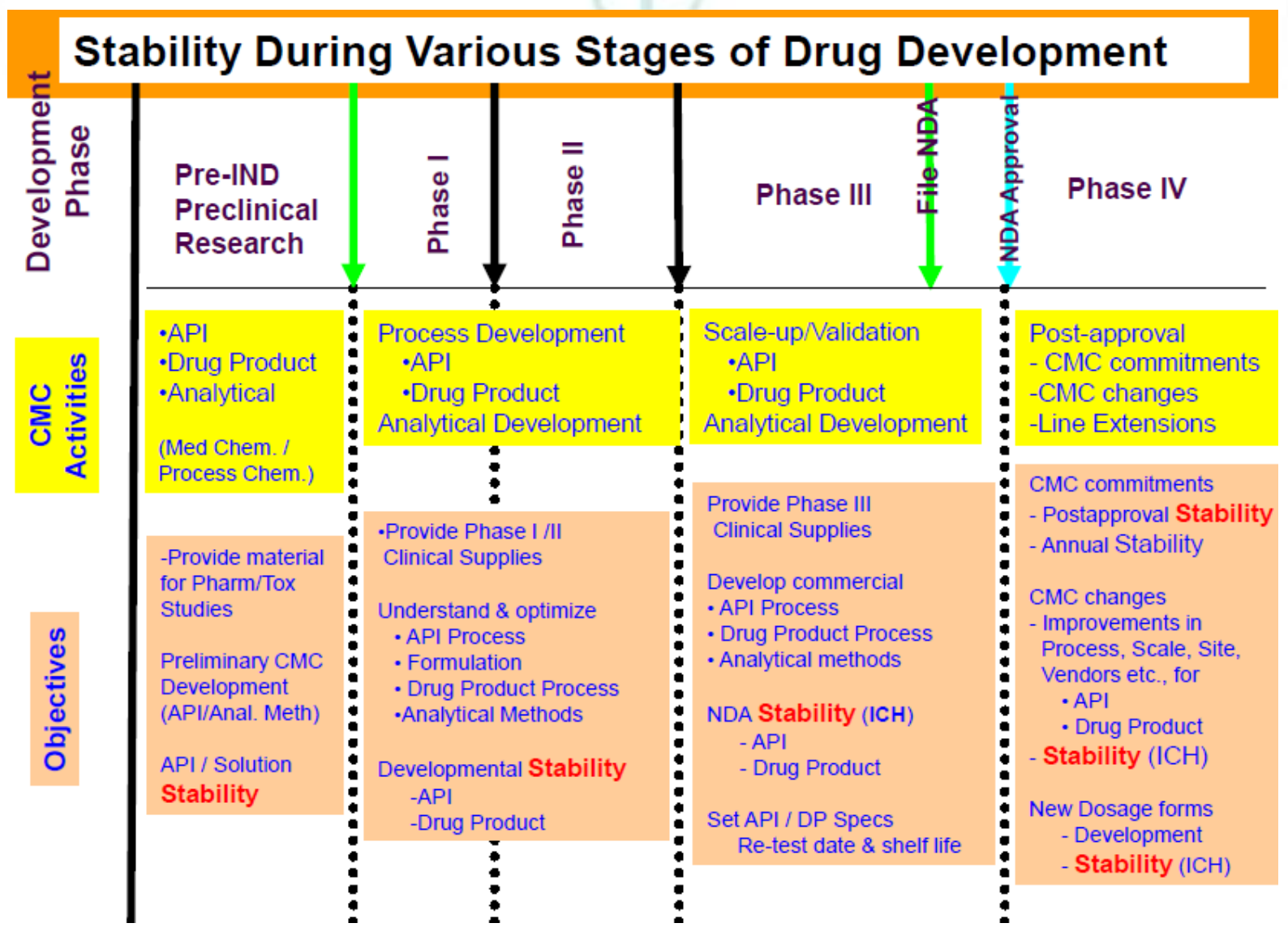

Figure 2: Stability during various stages of drug development. 


\section{GUIDELINE FOR STABILITY TESTING}

These guidelines include basic issues related to stability, the stability data requirements for application dossier and the steps for their execution. Such guidelines were initially issued in 1980s. These were later harmonized (made uniform) in the International Conference on Harmonization (ICH) in order to overcome the bottle neck to market and register the products in other countries. The ICH was a consortium formed with inputs from both regulatory and industry from European commission, Japan and USA. The World Health Organization (WHO), in 1996, modified the guidelines because the ICH guidelines did not address the extreme climatic conditions found in many countries and it only covered new drug substances and products and not the already established products that were in circulation in the WHO umbrella countries. In June 1997, US FDA also issued a guidance document entitled 'Expiration dating of solid oral dosage form containing Iron. WHO, in 2004, also released guidelines for stability studies in global environment ${ }^{7}$ (WHO, 2004). ICH guidelines were also extended later for veterinary products. A technical monograph on stability testing of drug substances and products existing in India has also been released by India Drug Manufacturers Association ${ }^{2}$. Further, different test condition and requirements have been given in the guidance documents for active pharmaceutical ingredients, drug products or formulations and excipients. The codes and titles for stability studies covered under ICH guidance have been outlined in the table.

Table 1: Codes and titles used in ICH Guidelines

\begin{tabular}{|l|l|}
\hline ICH Code & Guideline title \\
\hline Q1A & Stability testing of New Drug Substances and Products (Second Revision) \\
\hline Q1B & Stability testing : Photostability testing of New Drug Substances and Products \\
\hline Q1C & Stability testing of New Dosage Forms \\
\hline Q1D & Bracketing and Matrixing Designs for stability testing of Drug Substances and Products \\
\hline Q1E & Evaluation of stability data \\
\hline Q1F & Stability data package for Registration Applications in Climatic Zones 3 and 4 \\
\hline Q5C & Stability testing of Biotechnological/Biological Products \\
\hline
\end{tabular}

Q1 A (R2): Stability testing of new drug substances and products:

The purpose of stability testing is to provide evidence on how the quality of a drug substance or drug product varies with time under the influence of a variety of environmental factors such as temperature, humidity, and light, and to establish a re-test period for the drug substance or a shelf life for the drug product and recommended storage conditions.

Q1B: Stability testing: photostability testing of new drug substances and products:

The ICH Harmonized Tripartite Guideline covering the Stability Testing of New Drug Substances and Products (hereafter referred to as the Parent Guideline) notes that light testing should be an integral part of stress testing. This document is an annex to the Parent Guideline and addresses the recommendations for photo stability testing.

\section{Q1C: Stability Testing For New Dosage Forms}

New dosage form: A pharmaceutical product, containing the same active substance as included in the existing approved drug product, differing in:

- Route of administration (e.g., oral to parenteral)

- New functionality/delivery systems (e.g., immediate release to modified release tablet)

- Dosage forms / same administration route (e.g., capsule to tablet, solution to suspension) A reduced stability database at submission time (e.g., 6 months accelerated and 6 months long term data from on-going studies) may be acceptable in certain justified case.

\section{Q1D: BracketingandMatrixingDesigns}

Bracketing: Design of a stability schedule whereby only samples on the extremes of certain design factors (e.g., strength, container size and/or fill) are tested at alltime points as in a full design, assuming that the stability of any intermediate levels is represented by the stability of the extremes tested.

Matrixing: Design of a stability schedule where testing is performed on a selected subset of samples for one time point and on another subset of samples for a subsequent time point.

Get buy-in from the agency ahead of implementing a complex design

\section{Q1E: Evaluation of Stability Data}

The design and execution of formal stability studies should follow the principles outlined in the parent guideline. The purpose of a stability study is to establish, based on testing a minimum of three batches of the drug substance or product, a retest period or shelf life and label storage instructions applicable to all future batches manufactured and packaged under similar circumstances. The degree of variability of individual batches affects the confidence that a future production batch will remain within acceptance criteria throughout its retest period or shelf life.

Q1F -For Zones III and IV (Hot \& Dry or Hot \& Humid) 
ICH Q1 F Stability Data Package for Registration Applications in Climatic Zones III and IV defined storage conditions for stability testing in countries located in Climatic Zones III (hot and dry) and IV (hot and humid), i.e. countries not located in the $\mathrm{ICH}$ regions and not covered by ICH Q1 A (R2) Stability Testing for New Drug Substances and Drug Products. ICH Q1 F described harmonised global stability testing requirements in order to facilitate access to medicines by reducing the number of different storage conditions. In the course of the discussions which led to the development of the guideline, WHO conducted a survey amongst their member states to find consensus on $30^{\circ} \mathrm{C} / 65 \% \mathrm{RH}$ as the long-term storage conditions for hot and humid regions. As no significant objections were raised in this survey, $30^{\circ} \mathrm{C} / 65 \% \mathrm{RH}$ was defined as the long-term storage condition for Climatic Zone III/IV countries in ICH Q1F. The document was adopted by the ICH Steering Committee in February 2003 and subsequently implemented in the ICH regions.

\section{Q7: Good Manufacturing Practice Guide for Active Pharmaceutical Ingredients}

This document (Guide) is intended to provide guidance regarding good manufacturing practice (GMP) for the manufacturing of active pharmaceutical ingredients (APIs) under an appropriate system for managing quality. It is also intended to help ensure that APIs meet the requirements for quality and purity that they purport or are represented to possess. In this Guide "manufacturing" is defined to include all operations of receipt of materials, production, packaging, repackaging, labelling, relabeling, quality control, release, storage and distribution of APIs and the related controls. In this Guide the term "should" indicates recommendations that are expected to apply unless shown to be inapplicable or replaced by an alternative demonstrated to provide at least an equivalent level of quality assurance. For the purposes of this Guide, the terms "current good manufacturing practices" and "good manufacturing practices" are equivalent. The Guide as a whole does not cover safety aspects for the personnel engaged in the manufacture, nor aspects of protection of the environment. These controls are inherent responsibilities of the manufacturer and are governed by national laws. This Guide is not intended to define registration/filing requirements or modify pharmacopoeial requirements.

\section{CLIMATIC ZONE FOR STABILITY TESTING}

For the purpose of stability testing, the whole world has been divided into four zones (I - IV) depending upon the environmental conditions the pharmaceutical products are likely to be subjected to during their storage. These conditions have been derived on the basis of the mean annual temperature and relative humidity data in these regions. Based upon this data, long-term or real-time stability testing conditions and accelerated stability testing conditions have been derived.

Table 2: ICH Climatic zones and long term stability conditions

\begin{tabular}{|l|l|l|l|l|}
\hline $\begin{array}{l}\text { Climatic } \\
\text { Zone }\end{array}$ & Climate/Definition & Major Countries/Region & $\begin{array}{l}\text { MAT*/Mean annual partial } \\
\text { water vapour pressure }\end{array}$ & $\begin{array}{l}\text { Long-term testing } \\
\text { conditions }\end{array}$ \\
\hline I & Temperate & $\begin{array}{l}\text { UK, Northern Europe } \\
\text { Russia, United states }\end{array}$ & $<15^{\circ} \mathrm{C} /<11 \mathrm{hPa}$ & $21^{\circ} \mathrm{C} / 45 \% \mathrm{RH}$ \\
\hline II & $\begin{array}{l}\text { Subtropical and } \\
\text { Mediterranean }\end{array}$ & $\begin{array}{l}\text { Japan, Southern } \\
\text { Europe }\end{array}$ & $>15-22^{\circ} \mathrm{C} />11-18 \mathrm{hPa}$ & $25^{\circ} \mathrm{C} / 60 \% \mathrm{RH}$ \\
\hline III & Hot and Dry & Iraq, India & $>22^{\circ} \mathrm{C} /<15 \mathrm{hPa}>22^{\circ} \mathrm{C} />15-27$ & $30^{\circ} \mathrm{C} / 35 \% \mathrm{RH}$ \\
\hline IVa & Hot and humid & Iran, Egypt & $\mathrm{hPa}$ & $30^{\circ} \mathrm{C} / 65 \% \mathrm{RH}$ \\
\hline IVb & $\begin{array}{l}\text { Hot and very } \\
\text { Humid }\end{array}$ & Brazil, Singapore & $>22^{\circ} \mathrm{C} />27 \mathrm{hPa}$ & $30^{\circ} \mathrm{C} / 75 \% \mathrm{RH}$ \\
\hline
\end{tabular}

*MAT - Mean annual temperature measured in open air., ${ }^{2,9,10}$

\section{PROTOCOL FOR STABILITY TESTING}

The protocol for stability testing is a pre-requisite for starting stability testing and is necessarily a written document that describes the key components of a regulated and well-controlled stability study. Because the testing condition is based on inherent stability of the compound, the type of dosage form and the proposed container-closure system, the protocol depends on the type of drug substance or the product. In addition, the protocol can depend on whether the drug is new or is already in the market ${ }^{11}$.

\section{Batches:}

Stability studies at developmental stages are generally carried out on a single batch while studies intended for registration of new product or unstable established product are done on first three production batches, while for stable and well-established batches, even two are allowed. If the initial data is not on a full scale production batch, first three batches of drug product manufactured post-approval should be placed on longterm studies using the same protocol as in approved drug application. Data on laboratory scale batches obtained during development of pharmaceuticals are not accepted as primary stability data but constitute supportive information. In general, the selection of batches should constitute a random sample from the population of pilot or production batches ${ }^{1}$.

\section{Containers and closures:}

The testing is done on the product in immediate containers and closures proposed for marketing. The packaging materials include aluminium strip packs, blister packs, HDPE bottles etc. This may also include 
secondary packs, but not shippers. Products in all different types' of containers/closures, whether meant for distribution or for physician and promotional samples, are to be tested separately. However, for bulk containers, testing in prototype containers is allowed, if it simulates the actualpackaging ${ }^{1,2}$.

\section{Sampling time points:}

Frequency of testing should be such that it is sufficient to establish the stability profile of the new drug substance. For products with a proposed shelf life of at least 12 months, the testing frequency at the long-term storage condition should be every 3 months over the first year, every 6 months over the second year and annually thereafter throughout the proposed shelf life expiration date. In the case of accelerated storage conditions, a minimum of three time points, including the initial and end points, for example, 0, 3, and 6 months is recommended. When testing at the intermediate storage condition is necessary as a result of significant change at the accelerated storage condition, a minimum of four test points, including the initial and final time points, is recommended, for example, $0,6,9$ and 12 months $^{12}$.

Table 3: Test Schedule for stability testing of new products ${ }^{1,2}$

\begin{tabular}{|l|l|l|}
\hline Environment & $\begin{array}{l}\text { Sampling Time } \\
\text { Points (months) }\end{array}$ & Method \& Climatic zone \\
\hline $25^{\circ} \mathrm{C} / 60 \% \mathrm{RH}$ & $3,6,9,12,18,24,36$ & Long term for zones I and IV \\
\hline $30^{\circ} \mathrm{C} / 35 \% \mathrm{RH}$ & $3,6,9,12,18,24,36$ & Long term for zones III \\
\hline $30^{\circ} \mathrm{C} / 65 \% \mathrm{RH}$ & $3,6,9,12,18,24,36$ & Long term for zone IVa, or intermediate condition for zones I and II \\
\hline $30^{\circ} \mathrm{C} / 75 \% \mathrm{RH}$ & $3,6,9,12,18,24,36$ & Long term for zone IVa, or intermediate condition for zones I and II \\
\hline $40^{\circ} \mathrm{C} / 75 \% \mathrm{RH}$ & $3,6,9,12,18,24,36$ & Accelerated condition for all zones \\
\hline
\end{tabular}

\section{Test storage conditions:}

The storage conditions to be selected are based upon the climatic zone in which the product is intended to be marketed or for which the product is proposed to be filed for regulatory approval. General recommendations on the storage conditions have been given by ICH, CPMP and WHO.

Table 4: Stability test storage conditions for drug products ${ }^{7,9,12}$.

\begin{tabular}{|c|c|c|c|}
\hline $\begin{array}{l}\text { Intended storage } \\
\text { condition }\end{array}$ & $\begin{array}{l}\text { Stability Test } \\
\text { Method }\end{array}$ & $\begin{array}{l}\text { ICH Test temperature and } \\
\text { humidity (Period in months) }\end{array}$ & $\begin{array}{l}\text { WHO Test temperature and } \\
\text { humidity (Period in months) }\end{array}$ \\
\hline $\begin{array}{l}\text { Room } \\
\text { Temperature }\end{array}$ & Long term & $25 \pm 2^{\circ} \mathrm{C} / 60 \pm 5 \% \mathrm{RH}(12)$ & $\begin{array}{l}25 \pm 2^{\circ} \mathrm{C} / 60 \pm 5 \% \mathrm{RH} \text { or } \\
30 \pm 2^{\circ} \mathrm{C} / 65 \pm 5 \% \mathrm{RH} \\
30 \pm 2^{\circ} \mathrm{C} / 75 \pm 5 \% \mathrm{RH}(12)\end{array}$ \\
\hline Refrigerated & Long term & $5^{\circ} \mathrm{C} /$ ambient (12) & $5 \pm 3^{\circ} \mathrm{C}$ \\
\hline Freezer & Long term & $-20^{\circ} \mathrm{C} / \mathrm{ambient}(12)$ & $-20^{\circ} \mathrm{C} \pm 5^{\circ} \mathrm{C}$ \\
\hline
\end{tabular}

\section{Estimation of shelf life:}

The shelf life is determined from the data obtained from the long term storage studies. The data is first linearized and test for goodness of fit is applied. The linearized data is then analyzed to see that the slope and the intercepts are matching. Table 7 gives the different possibilities in the pattern of the concentration-time data of the three batches. The data is pooled accordingly and used for estimation of the common slope ${ }^{2}$.

\section{Recent trends in stability testing}

Current trend, especially amongst the multinational pharmaceutical companies, is to define conditions for stability testing for global marketing. For this the companies are orienting their protocols to single set of conditions that covers extreme environmental conditions. The specific changes for global testing include increase in duration of accelerated testing period from 6 to 12 months, and conduct of additional tests at $50^{\circ} \mathrm{C} / 75 \% \mathrm{RH}$ for 3 months ${ }^{13}$. The concept behind this change is to avoid repetition of stability testing for other regions and efficient and optimum use of resources as all tests are done in one laboratory. Moreover testing under combination of three environmental factors, viz., temperature, humidity and light, has been reported to result in stronger deleterious effect on drug substances and products, than under temperature and humidity conditions only ${ }^{1,2,14,15,16}$. 


\section{REFERENCES}

1. Bajaj S, Singla D, Sakhuja N, Stability Testing of Pharmaceutical Products, Journal of Applied Pharmaceutical Science. 2012; 02(03): 129-138

2. Singh S. Stability testing during product development in Jain NK Pharmaceutical product development CBS publisher and distributors. India, (2000) 272-293.

3. Kommanaboyina B., Rhodes CT. Trends in stability testing with Emphasis on Stability during Distribution and Storage. Drug Dev. Ind. Pharm. 1999; 25:857-867.

4. Rana A, Hari Kumar S. Manufacturing defects of tablets - a review. Journal of Drug Delivery and Therapeutics, 2013; 3(6):200-206. doi:10.22270/jddt.v3i6.722

5. Carstensen JT., Rhodes CT. Clin. Res. Drug Reg. Affairs. 1993; 10:177-185

6. Anderson G., Scott M. Determination of product shelf life and activation energy for five drugs of abuse. Clin. Chem. 1991; 37:398-402

7. WHO. Stability studies in a global environment. Geneva meeting working document QAS/05.146 with comments, (2004).

8. Mundhe A, Cocrystalization: an alternative approach for solid modification. Journal of Drug Delivery and Therapeutics, 2013; 3(4):166-172. doi:10.22270/jddt.v3i4.555

9. ICH Q1A (R2). Stability testing guidelines: Stability testing of new drug substances and products. ICH Steering Committee, 2003.

10. Grimm W. Extension of the international conference on harmonization tripartite guideline for stability testing of new drug substances and products to countries of climatic zones 3 and 4. Drug Dev. Ind. Pharm. 1998; 24:313-325

11. Ali J. Khar RK, Ahuja A. Dosage form and design.3rd ed. Delhi. Birla Publications Pvt. Ltd (2008) 100-123.

12. Cha J, Gilmor T, Lane P, Ranweiler JS. Stability studies in Handbook of modern pharmaceutical analysis. Separation Science and Technology. Elsevier (2001) 459-505.

13. Mischler PG. Developing Stability Protocols for Global Product Registrations-An Update. Presentation at International Seminar on Stability Testing: Design and Interpretation for International Registration, 13 and 14 February 2002, IBC Life Sciences, London.

14. Singh S, Bhutani H, Mariappan TT, Kaur H, Bajaj M, Pakhale SP. Behaviour of Uptake of Moisture by Drugs and Excipients under Accelerated Conditions of Temperature and Humidity in the Absence and the Presence of light. 1. Pure AntiTuberculosis Drugs and their Combinations. Int. J. Pharm. 2002; 245:37-44.

15. Bhutani H, Mariappan TT, Singh S. Behavior of Uptake of Moisture by Drugs and Excipients under Accelerated Conditions of Temperature and Humidity in the Absence and the Presence of light. Part 2. Packaged and Unpackaged antiTuberculosis drug products. Pharm. Technol. 2003; 27:44-52.

16. Shah D, Patel B, Shah C. Nanosuspension technology: a innovative slant for drug delivery system and permeability enhancer for poorly water soluble drugs. Journal of Drug Delivery and Therapeutics, 2015; 5(1):10-23. doi:10.22270/jddt.v5i1.995 